\title{
TRABALHANDO AS CONEXÕES INTERDISCIPLINARES ENTRE A LITERATURA E A HISTÓRIA NO PERÍODO PRÉ-COLONIAL E O PERÍODO COLONIAL NO TEATRO COMO METODO PEDAGOGICO
}

\author{
Winnie Rodrigues Holanda, Universidade Federal Capina Grande Iguatu-Ce, Brasil) \\ winnie-r@hotmail.com \\ Maria Do Livramento Alencar de Holanda, Universidade Estadual do Ceara, Iguatu-Ce, \\ Brasil \\ liliholanda@uol.com.br
}

\section{RESUMO}

A narrativa literária e a histórica possui uma conexão interdisciplinar desde os primeiros escritos que passaram a circular no "Novo Mundo". Temos os exemplos das literaturas de informação - escritas no Brasil - como a Carta de Pero Vaz, registros dos viajantes que descreviam os acontecimentos. Assim, objetivamos demostrar como podemos trabalhar de forma interdisciplinar os entrelaces existentes entre os campos da Literatura e da História, utilizando como recurso o teatro como forma de prática pedagógica em trabalhar as duas áreas. Configurando este estudo em uma análise metodológica de ensino, pautada na interdisciplinaridade entre literatura e história trabalhando o teatro na escola.

PALAVRAS-CHAVE: Interdisciplinaridade; Narrativa Literária; Historia.

\section{INTRODUÇÃO:}

Neste artigo procuramos apresentar algumas conexões interdisciplinares existentes entre os campos da História e da Literatura a partir das narrativas que se desenvolvem no período Pré-Colonial e o Período Colonial (1530 a 1822) diante da sociedade e sua história. Apresentando o envolvimento interdisciplinar entre as áreas com a pretensão de contribuir no processo de ensino utilizando como método pedagógico o teatro. Segundo Kaudela (2006) o teatro na educação é uma conquista, que vem ganhando espaço. No entanto muitos fatores ainda limitam e dificultam a sedimentação não apenas no que se refere às pesquisas teóricas como ao desenvolvimento de práticas significativas também. É visível e evidenciado que a utilização do teatro como prática pedagógica se reduz apenas à aplicação de técnicas 
desvinculadas de justificativa teórica e metodológica. Para que esse canário mude é necessário que se tenha uma contextualização entre o teatro e suas funções metodológicas. A interdisciplinaridade entre a narrativa literária e histórica torna-se um contexto a ser trabalhado de forma metodológica com uma vinculação teórica ao teatro na escola.

Apresentando assim a narrativa literária e histórica de forma única e interdisciplinar, partindo do princípio de que a literatura brasileira é presente na história do Brasil desde o período da colonização e sua história cultural, e de como é visível essa relação neste período histórico e literário. Sem esquecer de que uma trama narrativa ficcional pode desenvolver no teatro e podemos desenvolver através da encenação temas relacionados à história. Segundo Antônio Candido é insatisfatório o estudo da sociedade e a literatura, desde os tempos antigos. Então o teatro como forma de apresentação a este conhecimento é imprescindível para os alunos que irão participar façam essa relação entre a história e a literatura, pois a grande influência entre elas, que não devem ser esquecidas.

\section{DESENVOLVIMENTO:}

O teatro é uma ferramenta na qual contém uma abrangência perspectiva da prática pedagógica, o teatro envolve tanto quem encena como o receptor das apresentações dos espetáculos teatrais, tonando-se assim o teatro uma grande ferramenta para trabalhar a interdisciplinaridade, visto que tantos os alunos quem encenam como os espectadores alcançam o conhecimento das duas disciplinas diante ao espetáculo. Mas antes de toda a concepção da peça teatral é necessário que o professor ensine o período literário e histórico que será encenado em palco, aqui atribuído o período pré-colonial e o período colonial, tomando a relação de conexão entre a literatura e a história. Assim partimos do ideal de que a história sempre andou de mãos dadas com a literatura, quando observamos o conjunto histórico que envolve grandes contos literários, ou quando a história se torna literatura é visível o envolvimento entre estás duas disciplinas, e como é insatisfatório o trabalho diante desta relação, interdisciplinar e social. O Quinhentismo, Barroco e Arcadismo são escolas literárias brasileira que estão envolvidas com a história do Brasil no seu início, quando Pero Vaz de Caminha 
escreveu o primeiro documento falando acerca do "Novo Mundo" ali surgia a Literatura de Informação e o primeiro documento histórico escrito no Brasil. Antônio Candido faz uma crítica diante da carência de estudos que ocorram um envolvimento social e literário, na qual podemos atribuir também ao envolvimento histórico, já que quando falamos em sociedade articulamos todo o seu envolvimento histórico.

\begin{abstract}
"Do século passado aos nossos dias, este gênero de estudos tem permanecido insatisfatório, ou ao menos incompleto, devido à falta de um sistema coerente de referência, isto é, um conjunto de formulações e conceitos que permitam limitar. Objetivamente o campo de análise e escapar, tanto quanto possível, ao arbítrio dos pontos de vista." (ANTONIO,CANDIDO, 1985, pág:27)
\end{abstract}

A narrativa literária traz assuntos humanos, dos sentimentos, anseios e emoções, admitindo que o leitor se sinta na pele dos personagens, identificando-se com eles. Diante da imaginação, a narrativa busca com que o leitor se transfira para a atmosfera onde se desenvolve a história. Os textos literários normalmente são prazerosos, pois há uma relação entre personagem, história e o leitor. Já na narrativa histórica muitas vezes se esquece de que é necessário manter contato com os alunos do ensino básico, e com a sociedade em geral. Dessa forma, a produção histórica volta-se para dentro da academia, ou seja, é feita de história feita para historiadores, esquecendo de relacionar seus conteúdos com a educação básica. Mas é perceptível que os conteúdos das duas áreas estão em sua maioria conectadas, como as literaturas de catequese caráter religioso, foi considerada uma das iniciais manifestações literárias no Brasil, explorada sobretudo, pelos jesuítas, na qual foi atribuindo um papel literário e histórico no Brasil Colonial. E é diante destas duas disciplinas tão conectadas, que ainda não é possível encontrar esse envolvimento no âmbito escolar e até mesmo academicamente. Para Kramer (1995: 132), existe alguma classe de "batalha historiográfica" entre as áreas literárias e os que desejam manter a história em seus limites tradicionais. E por isso temos o teatro como prática pedagógica, visto que atualmente a literatura e história e a estética do teatro proveem um conteúdo e metodologias norteadoras para a teoria e prática educacional e interdisciplinar. A influência educacional do professor que irá utilizar do desenvolvimento do teatro é fundamental, que este desafie seus alunos ao 
processo de aprendizagem de reconstrução de significados. A perspectiva de interação entre o teatro e narrativa literatura e história é um aspecto a ser ressaltado.

CONCLUSÃO:

O presente trabalho tem como princípio demostrar como podemos trabalhar a interdisciplinaridade das narrativas literárias e histórica do período Pré-colonial e do período Colonial com teatro como metodologia de ensino, contribuindo com um ensino diferenciado e mais completo. Pois há uma grande defasagem quando se trata destes dois assuntos, tornando difícil o trabalho tanto interdisciplinar como o trabalho através da linguagem teatral. Entendemos então que a uma necessidade de um estudo mais aprofundado em relação a interdisciplinar entre a literatura e historia, principalmente quando o assunto é o período do Brasil Pré-Colonial e o período Colonial, que tem contribuição e assunto historio e literário que muitas vezes é esquecido essa relação com as devidas fundamentações. Enquanto ao teatro é necessário um maior aprofundamento sobre este método pedagógico de ensino na área interdisciplinar. O objetivo deste artigo foi mostrar a conexão existente entre a leitura e a história, trabalhando o teatro, e para que isso aconteça é necessário romper barreiras impostas pela as divisões de disciplinas, e a repetição de metodologias não ativas onde o teatro não é utilizado como ferramenta de ensino e aprendizagem.

\title{
WORKING THE INTERDISCIPLINARY CONNECTIONS BETWEEN LITERATURE AND HISTORY IN THE PRE-COLONIAL PERIOD AND THE COLONIAL PERIOD IN THE THEATER AS A PEDAGOGICAL METHOD
}

\begin{abstract}
The literary and historical narrative has an interdisciplinary connection since the first writings that began to circulate in the "New World". We have the examples of literatures of information - written in Brazil - as the Pero Vaz Letter, travelers' records describing the events. Thus, we aim to demonstrate how we can work in an interdisciplinary way the existing links between the fields of Literature and History,
\end{abstract}


using as a resource the theater as a form of pedagogical practice in working the two areas. Configuring this study in a methodological analysis of teaching, based on the interdisciplinarity between literature and history working the theater in the school.

KEY WORDS: Interdisciplinarity; Literary Narrative; History.

\author{
TRABAJANDO LAS CONEXIONES INTERDISCIPLINARES ENTRE LA \\ LITERATURA Y LA HISTORIA EN EL PERÍODO PRE-COLONIAL Y EL \\ PERÍODO COLONIAL EN EL TEATRO COMO METODO PEDAGOGICO
}

\begin{abstract}
RESUMEN
La narrativa literaria y la histórica posee una conexión interdisciplinaria desde los primeros escritos que pasaron a circular en el "Nuevo Mundo". Tenemos los ejemplos de las literaturas de información - escritas en Brasil - como la Carta de Pero Vaz, registros de los viajeros que describían los acontecimientos. Así, pretendemos demostrar cómo podemos trabajar de forma interdisciplinaria entre los campos de la Literatura y la Historia, utilizando como recurso el teatro como forma de práctica pedagógica en el trabajo de las dos áreas. En el análisis metodológico de la enseñanza, pautada en la interdisciplinaridad entre literatura e historia trabajando el teatro en la escuela.
\end{abstract}

PALABRAS CLAVE: Interdisciplinaridad; Narrativa Literaria; Historia. 


\section{REFERÊNCIAS BIBLIOGRÁFICAS:}

CANDIDO, Antônio. Literatura e sociedade: estudos de teoria e história literária. São Paulo: Nacional, 1985.

SANTANA, Arão Paranaguá (Coord.); SOUZA, Luiz Roberto; RIBEIRO, Tânia

Costa. Visões da ilha: Apontamentos sobre Teatro e Educação. São Luís, 2003. Teatro e Formação de Professores. São Luís: Editora da Universidade

Federal do Maranhão / EDUFMA, 2001.

KRAMER, Lloyd S. Literatura, crítica e imaginação histórica: o desafio literário de Hayden White e Dominick Lacapra. In: HUNT, Lynn. A Nova História Cultural. $1^{\text {a }}$ reimpressão. São Paulo: Martins Fontes, 1995.

KOUDELA. I. D. Pedagogia do Teatro. In: Congresso Brasileiro de Pesquisa e PósGraduação em Artes Cênicas (4: 2006: Rio de Janeiro). Anais/ do IV Congresso Brasileiro de Pesquisa e Pós-Graduação em Artes Cênicas. Organização RABETTI, Maria de Lourdes. Rio de Janeiro: 7Letras, 2006. 